\title{
Development of A Training Model for Working with Young Children in The Conditions of a Master's Program and Additional Education in A Pedagogical University
}

\author{
Alexander Ilich Savenkov ${ }^{1 *}$, Olga Andreyevna Lyubchenko $^{1}$, Sergey Georgievich \\ Vorovshchikov $^{1}$, and Anna Sergeevna Lvova ${ }^{1}$ \\ ${ }^{1}$ Moscow City University, Moscow, Russia
}

\begin{abstract}
The paper presents and characterizes an integrative model of teacher training for working with young children. The purpose of the study is to develop a universal model that ensures the fulfillment of the society's demand for the training of teachers in course of master's programs and continuing pedagogical education, to help eliminate the shortage of professional staff in preschools. The model has been developed under the competence paradigm of education and taking into account the requirements of federal state educational standards of higher education and the professional standards for teachers in the conditions of coherence between the work-related activities (functions) and competencies. The universality of the model is determined by a unified educational outcome, content, forms, and technologies, as well as indicators and criteria for the effective preparation of teachers for working with young children both in the framework of their master's program and in the continuing education system.
\end{abstract}

\section{Introduction}

The relevance of developing a teacher training model for working with young children is determined by the need for teachers at Moscow pre-schools. Note that the need for preschool teachers is only increasing due to the continuing construction of new preschools and reconstruction of existing ones [1-6].

Reviewing in detail the target component of the development of the model as ensuring the professional readiness of teachers to work with young children in nursery groups of educational organizations in Moscow, let us define the tasks that need to be solved to achieve the stated goal:

1. Determine the educational outcome of teacher training.

2. Define the content of teacher training.

3. Designate forms and educational technologies for teacher training.

4. Develop criteria and indicators of the effectiveness of teacher training.

* Corresponding author: asavenkov@bk.ru 
The solution of the indicated tasks has been developed taking into account the existing modern regulatory documents in the system of higher and continuing education.

\section{Methods}

Modeling the training system for working with young children determines the planned educational outcome as an indicator of the effectiveness of the proposed model, developed taking into account the requirements of the Federal state educational standard for higher education (FGOS VO) and the teachers' professional standard, the coherence between the work-related activities (functions) and competencies.

The structure of the planned educational outcome is made up of the following training components:

- the cognitive component, including professional self-esteem, knowledge, competences, professional skills: possession of the Gnostic, constructive, informational and explanatory functions of pedagogical activities;

- the personal component, characterized by satisfaction with the chosen profession, as a way of self-realization, adoption of a system of motives, values, and norms of the pedagogical community; possession of the mobilizing, organizing, communicative functions of pedagogical activities;

- the instrumental component, consisting of the teacher's work-related behavior, the desire to remain in the profession, and make progress in it; possession of generalized labor functions for the design and implementation of the educational process and educational programs.

It follows from the structure that the educational outcome is a characteristic of the teacher's personality, consisting of professionally significant personal qualities, value orientations, knowledge, skills and professional activities that can effectively act in rapidly changing socio-economic conditions, meet the requirements of the state, society, employers, achieve competitive advantages in their professional activities.

\section{Results}

The determinant of the effectiveness of the integrative model of training teachers for working with young children is the content of educational programs in the master's programs and the retraining programs for continuing professional education developed following the model.

The professional component of teacher training in the main educational process of the master's program is determined by two invariant modules.

The "Scientific and methodological foundations of early childhood" module includes the following aspects:

- providing a system of integrative knowledge regarding perinatal psychology, pedagogy, and medicine;

- associated with the study, analysis, and use in practical work of modern Russian and foreign concepts on the development of young children;

- forming a system of knowledge about disease symptoms and prevention, basic modern hygiene, and pediatric practices in children during early childhood.

The "Technologies for the education and training of infants and young children" module includes the following aspects:

- preparing for teaching young children, including by developing and implementing basic educational programs;

- defining basic skills in organizing the students' life and the implementation of the educational process; 
- providing pedagogical support for the development of children in the conditions of the subject-spatial environment of a preschool.

The modules include elective courses that form a system of knowledge about the social and personal development of children in early childhood; psychological and pedagogical counseling of parents; designing individual educational routes for children with special needs and others.

The training of teachers in the system of continuing education involves two theoretical modules, while the internship (practice) represents a separate third module.

The "Theory and technology of working with young children in nursery groups of Moscow educational institutions" module is represented by courses on perinatal pedagogy, pedagogical technologies for the development, upbringing, and education of children in early childhood, designing a developing subject-spatial environment in young groups.

The "Psychological and pedagogical support and designing work with young children in nursery groups" module includes subjects for planning and organizing the educational process in young groups, adapting children to the conditions of educational organization, designing individual educational routes for children with special needs, psychological and pedagogical support for families with young children.

The internship is aimed at studying the state and potential of the educational system and its macro- and microenvironment and at preparing to research, organize and evaluate work with young children in nursery groups of educational organizations.

The implementation of the content of integrated teacher training for working with young children requires various forms of education:

- full-time, combined full-time and part-time, part-time (using distance learning) at the macro level;

- traditional (lectures, seminars, workshops, colloquia, independent work, research work, various types of practices) and innovative (masterclasses, lecture conferences, binary lectures, provocative lectures, educational battles, workshops, edutainment conferences) at the micro-level [7].

The use of distance learning at the macro level makes teacher training affordable, economical, and flexible.

When training a teacher, it is advisable to use various educational technologies:

- search technologies (discussion, research, design, and others);

- imitation (role-playing games, business games, debates, round tables, and others);

- non-simulation methods (research, analysis of specific situations, organization and activity game, and others).

In general, the content-related component of the model using various forms and technologies determines the result of the educational process for students as the ability:

- to develop a sequence of educational tasks aimed at maintaining and strengthening health, psychological development and personality formation of students taking into account their characteristics;

- to carry out and optimize preventive and correctional work with various categories of students, to demonstrate advanced professional experience in the team;

- to conduct an expert assessment of the educational environment and methodological support of the educational activities of the educational organization and develop recommendations for improving their quality. 


\section{Discussion}

The results obtained in the study require the designation of criteria and performance indicators of the model that correspond to the content of the training and the designated educational outcome.

In psychological and pedagogical theory and practice, one can find various characteristics of a qualitative assessment of teacher training. It is believed that the effectiveness of pedagogical activities depends on individual and personality characteristics, professional knowledge, skills, and social qualities, which also corresponds to the components of teacher training that we have identified (cognitive, personal, instrumental, etc.) $[8,9]$.

The value-based and motivational component does not have a special independent status, but it is an integral part of each of the selected components of teacher training.

We define the following criteria for the effectiveness of preparing a teacher for working with young children.

The cognitive criterion including evaluation:

- of the pedagogical knowledge and ideas about how to use them in situations of educational practice;

- of the pedagogical thinking, as the ability to operate with professional concepts and judgments, to justify one's point of view, including in the practice of educational activities;

- of pedagogical creativity.

The personal criterion (level of social competence) includes:

- value-based orientations (the social orientation);

- social reflection (awareness of responsibility for one's actions and results of one's activities);

- self-acceptance and tolerance.

The instrumental criterion determines the dynamics of motivation in terms of mastering work-related functions (actions), the level of formation of work-related functions in terms of designing and implementing the educational process, and designing educational programs.

We suggest evaluating the degree of manifestation for each criterion which allows us to assess the level of teacher training by level.

The low level is characterized by a small amount of pedagogical knowledge and the lack of creative pedagogical thinking. This level is characterized by weak volitional regulation, lack of faith in the success of the professional activity, or excessive self-confidence. The teacher does not rely on any value-based system in their professional pedagogical activities. They cannot apply their knowledge on the design and implementation of the educational process and the design of educational programs, there are no dynamics in the development of their work-related functions, work-related activities, the formation of competencies.

The average level is characterized by professional knowledge and the presence of elements of creative pedagogical thinking. Pedagogical thinking is expressed in the ability to analyze, compare, and generalize the elements of professional activity. At the average level, the teacher relies on a system of values in their professional activity, expresses a desire for self-development with elements of professional reflection and social responsibility for their actions, but with an increased level of anxiety for the results of their work. Professional activity at this level is mainly reproductive, the teacher can analyze the elements of the educational process and educational programs abut cannot design or implement the educational process or educational programs $[10,11,12]$. There is a positive trend in the development of work-related functions, work-related actions, the formation of competencies.

The high level is characterized by the completeness and consistency of theoretical knowledge, its modification (association) taking into account practical experience, the presence of creative flexible pedagogical thinking. This level is characterized by such personal qualities as cognitive activity, self-discipline, the pursuit of excellence, the ability 
to lead, the ability to predict the results of one's activities, and the readiness for justified risk. This level is determined by a high motivational readiness for productive professional activity, an understanding of its social significance, and acceptance of social responsibility for the results of activities. The teacher can design and implement the educational process, educational programs, demonstrates a high degree of development of work-related functions, work-related actions, and the formation of competencies.

Consequently, a teacher with a high level of professional readiness to work with young children will be a competitive specialist in the job market.

\section{Conclusion}

The implementation of the presented model will allow to eliminate the staff shortage of teachers in preschools, increase the willingness of the teacher to implement the educational process in groups of young children, including the design and implementation of the main educational programs of the master's program and continuing education programs, taking into account:

- the presented educational outcome of teacher training with the cognitive, personal and instrumental structural components;

- determining the content of training for working with young children in the master's program and the continuing education system aimed at obtaining the educational outcome presented in the model;

- updating forms and technologies for teacher training (with a focus on productive and interactive forms);

- development of criteria and indicators of the effectiveness of training for working with young children.

The presented integrative model is open and, in the future, may become the subject of separate studies in the field of teacher training in higher education and continuing education systems.

\section{References}

1. S.G. Vorovshchikov, O.A. Lyubchenko, Pedagog. Educ. Sci. 1, 7-11 (2020)

2. S. G. Vorovshchikov, Pedagog. Educ. Sci. 5, 4-9 (2012)

3. O. L. Zvereva, A. N. Ganicheva, Family pedagogy and home education of children of early and preschool age (Yurayt Publishing House, Moscow, 2016)

4. A. S. Lvova, O.A. Lyubchenko, Bul. Moscow City Pedagog. Univ. Series Pedagog. Psy. 1(35) 89-96 (2016)

5. A. I. Savenkov, A. S. Lvova, O. A. Lyubchenko, Modern high technol. 8, 218-222 (2018)

6. A.I. Savenkov, O.V. Tsaplina, A.N. Ganicheva, Monitoring of the main educational programs of preschool education: teaching aid (Publishing house of VITITSART, Moscow, 2017)

7. L.S. Podymova, V.A. Slastenin, Pedagogy: textbook and workshop for secondary vocational education (Publishing house Yurayt, Moscow, 2016)

8. O.A. Lyubchenko, A.S. Lvova, Humanit. Soc. Sci. 4,127-134 (2015)

9. D.V. Caprar, B. Do, J.M. Bartunek, S.L. Rynes, Academy Manag. Learn. Educ. 15(2), 207-231 (2016)

10. O.A. Lyubchenko, A.S. Lvova, Yu.A. Popov, A.P. Kaitov, Teaching practice in undergraduate and graduate courses: concept, content, methodology: teaching aid. 
(Publishing House "Pero", Moscow, 2015)

11. A.I. Savenkov, O.V. Tsaplina, N.B. Polkovnikova, P.V. Smirnova, N.S. Murodhodzhaeva, T.D. Savenkova, The development of figurative thinking of a preschooler in the process of visual modeling (SIC ART, Moscow, 2019)

12. N. Rupcic, Lear. Org. 27(2), 173-180 (2020) 